\title{
PERANCANGAN APLIKASI PENGAMANAN INFORMASI TEKS DENGAN MENGGUNAKAN ALGORITMA KRIPTOGRAFI ALPHA-QWERTY REVERSE
}

\section{DESIGN OF TEXT INFORMATION SECURITY APPLICATION USING CRYPTOGRAPHIC ALGORITHM OF ALPHA-QWERTY REVERSE}

\author{
Muhammad Eka Putra ${ }^{1}$, Suroso $^{2}$, Adewasti $^{3}$ \\ ${ }^{1,2,3}$ Program Studi Teknik Telekomunikasi, Jurusan Teknik Elektro \\ Politeknik Negeri Sriwijaya,

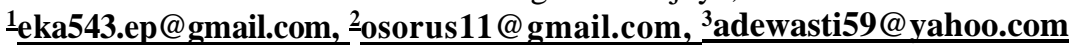

\begin{abstract}
Abstrak
Alpha-qwerty reverse merupakan salah satu bagian dari algoritma kriptografi klasik yang berfungsi sebagai pengamanan informasi dengan melakukan penyandian terhadap informasi. Proses penyandian terhadap informasi tersebut yaitu enkripsi dan deskripsi. Algoritma alphaqwerty reverse merupakan pengembangan dari algoritma kriptografi vigenere cipher. Alphaqwerty reverse memiliki perbedaan yaitu dari segi jumlah karakternya yang lebih banyak dari vigenere cipher di mana alpha-qwerty reverse menggunakan 92 karakter sedangkan vigenere cipher hanya menggunakan 26 karakter. Selain itu, dari segi pemakaian karakternya juga berbeda. Pada vigenere cipher, karakter yang digunakan merupakan urutan alfabet baik pada pesan asli (plaintext), kunci maupun pesan tersandi (ciphertext) sedangkan pada alpha-qwerty reverse menggunakan urutan alfabet dari keyboard pada plaintext dan kunci. Oleh karena itu, pada penelitian ini akan merancang aplikasi pengamanan informasi yaitu teks dengan algoritma kriptografi alpha-qwerty reverse menggunakan perangkat lunak eclipse. Tujuan dari perancangan aplikasi yaitu untuk mengamankan informasi teks penting yang terdapat pada telepon seluler berbasis android dengan tujuan untuk disimpan atau dikirimkan melalui layanan komunikasi telepon seluler. Dari penelitian ini dapat disimpulkan bahwa algoritma kriptografi alpha-qwerty reverse dapat diimplementasikan pada aplikasi pengamanan informasi teks yang dirancang dan sebagai algoritma kriptografi terbaru yang dapat mengamankan informasi dengan menghasilkan tingkat keamanan yang lebih baik.
\end{abstract}

Kata kunci : alpha-qwerty reverse, android, aplikasi pengamanan informasi, enkripsi, deskripsi, teks

\begin{abstract}
Abstract - Alpha-qwerty reverse is one part of the classical cryptographic algorithm that serves as the security of information by encoding to information. The process of encryption of that information is encrypted and description. Alpha-qwerty reverse algorithm is a development of vigenere cipher cryptographic algorithms. Alpha-qwerty reverse differences in terms of number of characters that are more than vigenere cipher in which the alpha-qwerty reverse using 92 characters while vigenere cipher uses only 26 characters. Moreover, in terms of the use of character is also different. In vigenere cipher, the characters used an alphabet sequence either in the original message (plaintext), a key or an encrypted message (ciphertext) whereas the alpha-qwerty reverse using the alphabetical order of the plaintext and key keyboard. Therefore, in this study will design a security application that is text information with the cryptographic algorithm of alpha-qwerty reverse using a eclipse software. The aim of designing applications, namely to secure the important text information contained in the mobile phone based on android with the purpose of storing or transmitting through a mobile
\end{abstract}


phone communication service. From this study it can be concluded that alpha-qwerty reverse cryptographic algorithms can be implemented on the text information security applications designed and as the latest cryptographic algorithms to secure the information by generating a better level of security.

Keywords: alpha-qwerty reverse, android, information security application, encryption, description, text

\section{PENDAHULUAN}

Kriptografi dapat didefinisikan sebagai seni maupun ilmu yang menghasilkan pesan yang rahasia [1]. Sebuah pesan asli yang disebut sebagai plaintext disandikan menjadi pesan yang tersandi yang disebut sebagai ciphertext melalui proses enkripsi dan ciphertext dipulihkan menjadi plaintext kembali melalui proses deskripsi [2]. Kriptografi memiliki beragam algoritma yang telah banyak digunakan sebagai keamanan untuk informasi [3]. Algoritma kriptografi memiliki dua jenis yaitu algoritma kriptografi klasik dan algoritma kriptografi modern. Dalam pengoperasiannya, algoritma kriptografi klasik bekerja menggunakan mode karakter sedangkan algoritma kriptografi modern bekerja menggunakan mode bit.

Saat informasi teks disandikan menggunakan algoritma kriptografi pada proses enkripsi, maka informasi yang tersandi akan melebihi ukuran jumlah teks dari informasi aslinya, bahkan bisa dua hingga empat kali ukuran informasi aslinya [1]. Oleh karena itu, pada penelitian ini akan menggunakan algoritma kriptografi klasik. Algoritma kriptografi klasik yang digunakan pada penelitian ini adalah algoritma kriptografi alpha-qwerty reverse. Algoritma kriptografi alpha-qwerty reverse merupakan pengembangan dari algoritma kriptografi klasik vigenere cipher dan menggunakan 92 karakter pada proses enkripsi maupun deskripsinya [4].

Di dalam penelitian ini akan melakukan perancangan aplikasi pengamanan informasi teks menggunakan algoritma kriptografi alpha-qwerty reverse. Tujuan dari penelitian ini yaitu untuk menyandikan informasi teks penting yang terdapat pada telepon seluler guna untuk disimpan atau dikirimkan melalui layanan komunikasi seperti SMS dan sosial media dengan maksud melindungi informasi tersebut dari berbagai ancaman pencurian informasi oleh orang yang tidak berhak menerimanya. Informasi tersebut seperti data perusahaan, chat personal, rekening bank dan lain-lain.

\section{DASAR TEORI /MATERIAL}

Alpha-qwerty reverse merupakan salah satu algoritma kriptografi klasik yang telah dikembangkan dari algoritma kriptografi vigenere cipher. Alpha-qwerty reverse memiliki rencana untuk memperpanjang karakter vigenere cipher yang memiliki jumlah karakter sebanyak 26 buah menjadi 92 buah. Selain itu, alpha-qwerty reverse mengubah pemetaan urutan alfabet yang dilakukan oleh vigenere cipher. Pemetaan yang digunakan dalam alpha-qwerty reverse yaitu menggunakan urutan teks keyboard [4].

Pada prosesnya, algoritma kriptografi alpha-qwerty reverse mirip dengan algoritma kriptografi alpha-qwerty di mana algoritma kriptografi alpha-qwerty juga merupakan salah satu algoritma kriptografi yang telah dikembangkan dari algoritma kriptografi vigenere cipher [5]. Algoritma kriptografi alpha-qwerty menggunakan urutan alfabet pada plaintext serta kunci dan urutan teks keyboard hanya pada ciphertext sedangkan alpha-qwerty reverse menggunakan urutan alfabet pada ciphertext dan urutan teks keyboard pada plaintext serta kunci [4].

Karakter plaintext alpha-qwerty reverse, urutan alfabet adalah [4]:

[q-z, Q-Z, ‘ $\left.\sim ! @ \# \% \wedge \& *()_{-}=+\{\}[] \mid ;: ’>, ? /, 0-9\right]$

Karakter ciphertext alpha-qwerty reverse, urutan teks keyboard adalah [4]: 
[a-z, A-Z, 0-9, ‘ !@\#\$\%^\&*()_- =+\{\}[]|;:”॰,.?/ ]

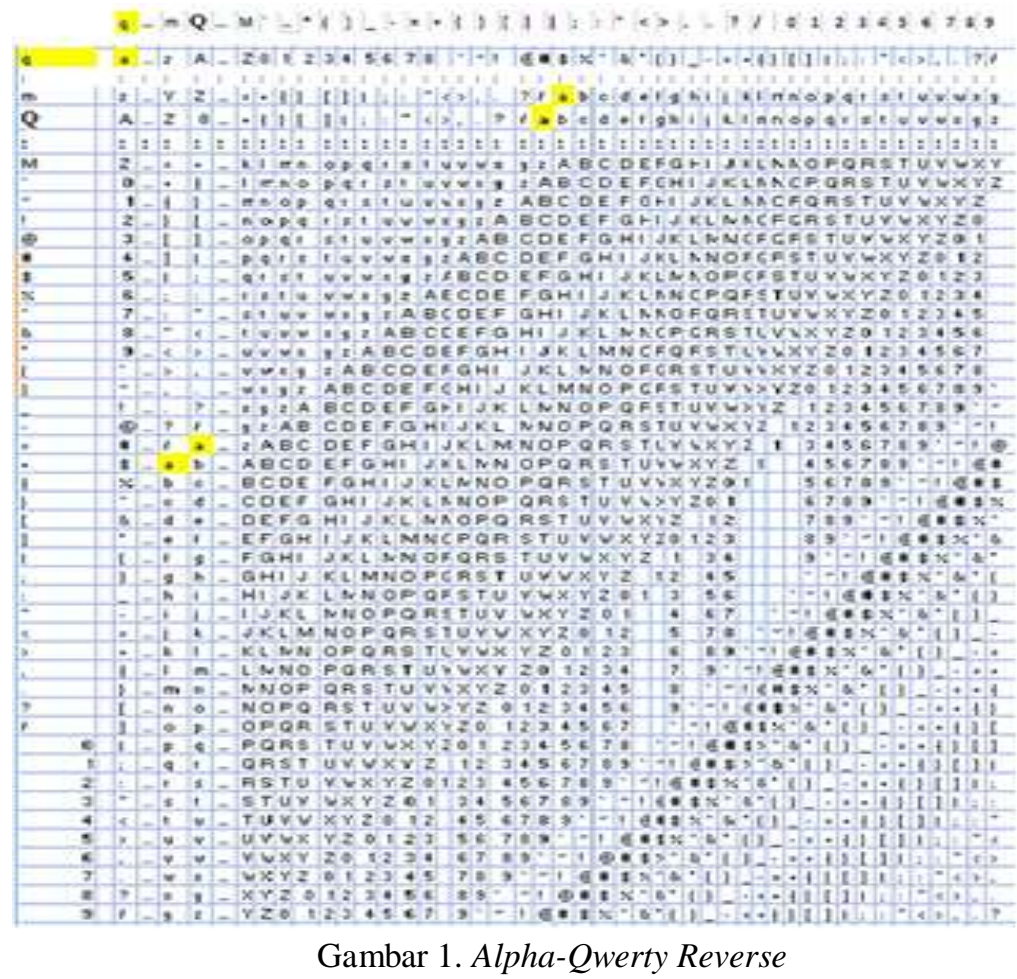

\section{METODOLOGI/PERANCANGAN}

Perancangan aplikasi pada penelitian ini terbagi menjadi dua bagian yaitu perancangan desain (.xml) dan perancangan perintah program (.java). Perancangan tersebut diawali dengan perancangan desain aplikasi. Di dalam penelitian ini, desain tampilan yang telah dirancang akan diuji apakah sesuai dengan yang diharapkan. Setelah pengujian tersebut, dilakukan perancangan perintah program pada aplikasi. Seperti halnya pada perancangan desain, pengujian juga akan dilakukan pada perintah program aplikasi.

\subsection{Perancangan Desain Tampilan Aplikasi}

Perancangan desain tampilan merupakan perancangan untuk tampilan aplikasi yang dilakukan pada layout di dalam software eclipse. Pada layout memiliki pilihan widget seperti tombol, teks, images dan lain-lain yang dapat diatur sesuai dengan desain yang diinginkan. Pembuatan desain dapat dilakukan pada file XML atau Graphical Layout di dalam software. Pada flie XML, widget dapat diatur menggunakan koding sedangkan pada graphical layout, widget dapat diatur secara manual.

- Rancangan Tampilan Menu Utama

Pada perancangan ini memiliki dua menu yang diantaranya yaitu enkripsi dan deskripsi. Pada menu enkripsi, desain akan diatur menggunakan widget berupa tombol. Dari tombol tersebut, tampilan menu utama diatur menuju ke tampilan enkripsi. Begitu juga dengan menu deskripsi yang menggunakan widget berupa tombol. Pada tombol deskripsi akan diatur menuju ke tampilan deskripsi. Rancangan tampilan menu utama dapat terlihat pada Gambar 2. 


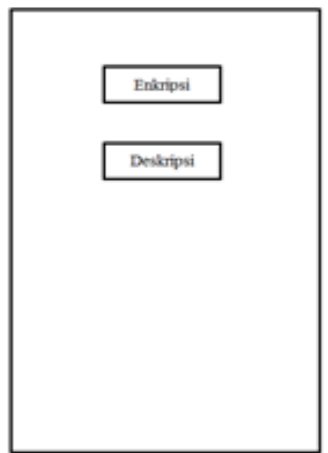

Gambar 2. Rancangan Tampilan Menu Utama

- $\quad$ Rancangan Tampilan Enkripsi

Pada perancangan ini memiliki menu yang diantaranya yaitu plaintext, kunci, proses, back dan ciphertext. Pada menu plaintext, kunci dan hasil (ciphertext), desain akan diatur menggunakan widget berupa text view sedangkan menu proses dan back menggunakan widget berupa tombol. Pada menu proses akan diatur untuk menampilkan hasil ciphertext dan menu back diatur untuk menuju ke tampilan menu utama. Rancangan tampilan enkripsi dapat terlihat pada Gambar 3.

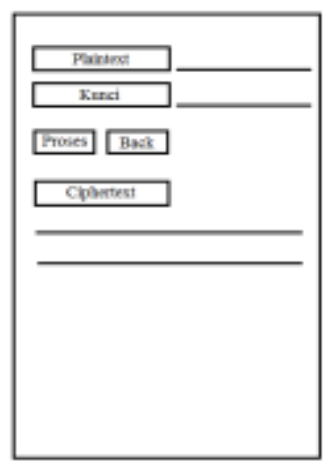

Gambar 3. Rancangan Tampilan Enkripsi

- Rancangan Tampilan Deskripsi

Pada perancangan ini memiliki menu yang diantaranya yaitu ciphertext, kunci, proses, back dan hasil (plaintext) Pada menu chipertext, kunci dan plaintext, desain akan diatur menggunakan widget berupa text view sedangkan menu proses dan back menggunakan widget berupa tombol. Pada menu proses akan diatur untuk menampilkan hasil plaintext dan menu back diatur untuk menuju ke tampilan menu utama. Rancangan tampilan deskripsi dapat terlihat pada Gambar 4.

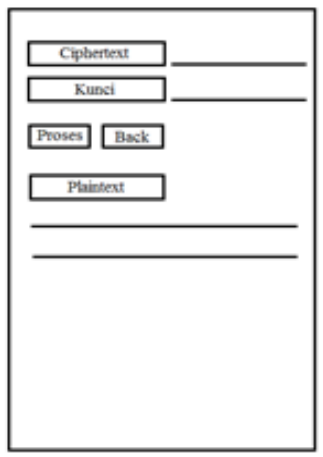

Gambar 4. Rancangan Tampilan Deskripsi 


\subsection{Perancangan Perintah Aplikasi}

Di dalam perancangan ini dilakukan proses enkripsi dan deskripsi. Proses enkripsi berfungsi untuk mengamankan informasi dengan cara mengenkripsi plaintext dengan kunci. Pada proses deskripsi berfungsi untuk membuka informasi dengan cara mendeskripsi ciphertext dengan kunci. Flowchart perancangan perintah program menu enkripsi dapat terlihat pada Gambar 5 dan deskripsi pada Gambar 6.

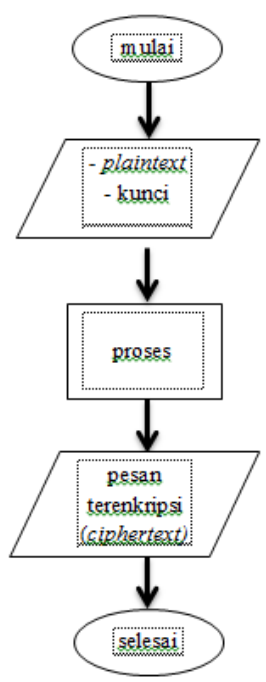

Gambar 5. Flowchart Perancangan Perintah Program Menu Enkripsi

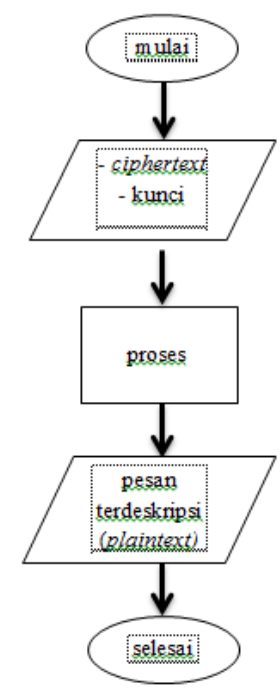

Gambar 6. Flowchart Perancangan Perintah Program Menu Deskripsi

Pada proses algoritma kriptografi alpha-qwerty reverse memiliki dua pemetaan karakter yang digunakan dalam perancangan perintah program yaitu urutan alfabet dan urutan teks keyboard. Urutan teks keyboard digunakan untuk plaintext dan kunci sedangkan urutan alfabet digunakan untuk ciphertext. Berikut flowchart proses algoritma pada enkripsi dapat terlihat pada Gambar 7 dan pada deskripsi dapat terlihat pada Gambar 8. 


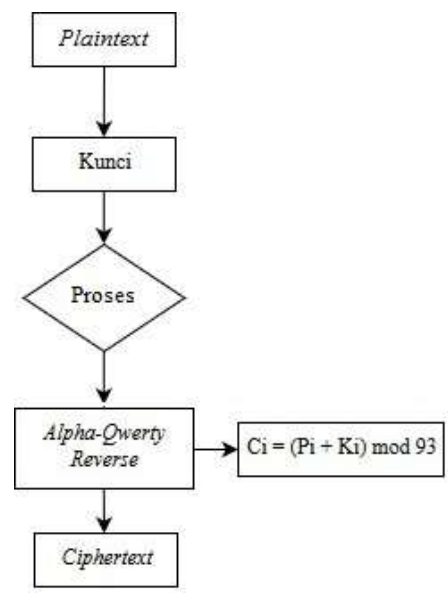

Gambar 7. Flowchart Proses Algoritma pada Enkripsi

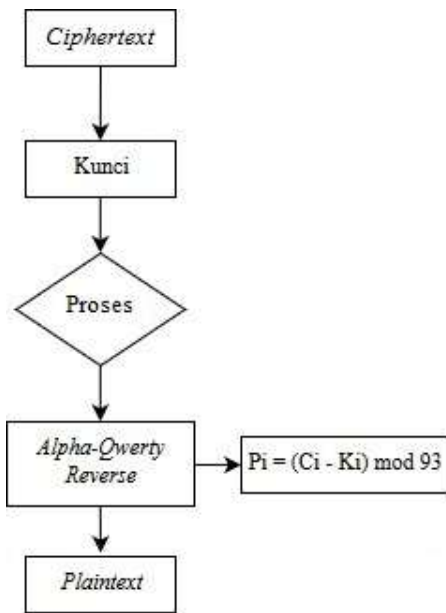

Gambar 8. Flowchart Proses Algoritma pada Deskripsi

\section{PEMBAHASAN}

\subsection{Tampilan Aplikasi}

Pada penelitian ini didapatkan tampilan pada aplikasi yang memiliki 3 tampilan yaitu tampilan menu utama pada Gambar 9, tampilan enkripsi pada Gambar 10 dan tampilan deskripsi pada Gambar 11.

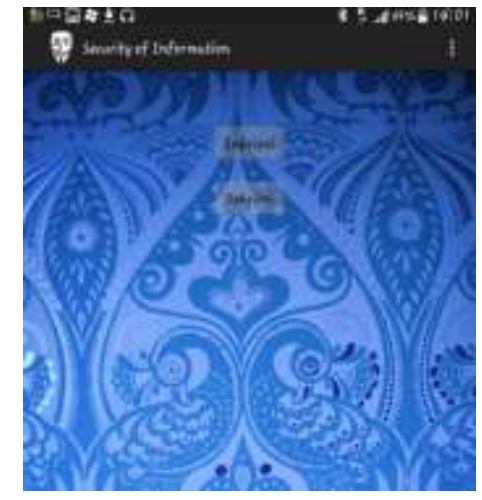

Gambar 9. Tampilan Menu Utama 

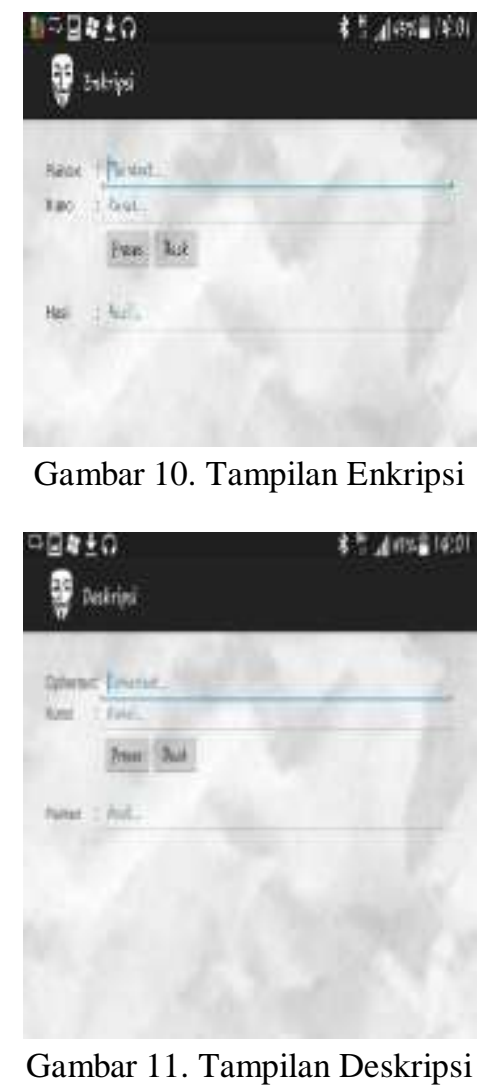

\subsection{Tampilan Aplikasi}

Pada Pada penelitian ini dilakukan pengujian terhadap enkripsi dan juga pengujian terhadap deskripsi. Pengujian ini dilakukan untuk melihat apakah proses enkripsi dan deskripsi aplikasi yang dibuat sesuai dengan teori atau tidak di mana teori yang digunakan yaitu algoritma kriptografi alpha-qwerty reverse.

Pada enkripsi akan dilakukan pengujian menggunakan plaintext yaitu "Sriwijaya123" pada Tabel 1 dan deskripsi menggunakan ciphertext yaitu "UlzmkxtnCd $>$ ?" pada Tabel 2 dengan kunci "polsri”. Berikut pengujian enkripsi dan deskripsi yang dilakukan dapat terlihat pada tabel.

Tabel 1 Pengujian Enkripsi

\begin{tabular}{|c|c|c|c|c|}
\hline Plaintext & Kunci & $\begin{array}{c}\text { Ciphertext } \\
\text { (Aplikasi) }\end{array}$ & $\begin{array}{c}\text { Ciphertext } \\
\text { (Teori) }\end{array}$ & Indikator \\
\hline S & $\mathrm{p}$ & $\mathrm{U}$ & $\mathrm{U}$ & Sama \\
\hline $\mathrm{R}$ & $\mathrm{o}$ & $\mathrm{l}$ & $\mathrm{l}$ & Sama \\
\hline $\mathrm{I}$ & $\mathrm{l}$ & $\mathrm{z}$ & $\mathrm{z}$ & Sama \\
\hline $\mathrm{W}$ & $\mathrm{s}$ & $\mathrm{m}$ & $\mathrm{m}$ & Sama \\
\hline $\mathrm{I}$ & $\mathrm{r}$ & $\mathrm{k}$ & $\mathrm{k}$ & Sama \\
\hline $\mathrm{J}$ & $\mathrm{i}$ & $\mathrm{x}$ & $\mathrm{x}$ & Sama \\
\hline $\mathrm{A}$ & $\mathrm{p}$ & $\mathrm{t}$ & $\mathrm{t}$ & Sama \\
\hline $\mathrm{Y}$ & $\mathrm{o}$ & $\mathrm{n}$ & $\mathrm{n}$ & Sama \\
\hline $\mathrm{A}$ & $\mathrm{l}$ & $\mathrm{C}$ & $\mathrm{C}$ & Sama \\
\hline 3 & $\mathrm{~s}$ & $\mathrm{~d}$ & $\mathrm{~d}$ & Sama \\
\hline 2 & $\mathrm{r}$ & $>$ & $>$ & Sama \\
\hline I & $\mathrm{i}$ & $?$ & $?$ & Sama \\
\hline
\end{tabular}


Tabel 2 Pengujian Deskripsi

\begin{tabular}{|c|c|c|c|c|}
\hline Ciphertext & Kunci & $\begin{array}{c}\text { Plaintext } \\
\text { (Aplikasi) }\end{array}$ & $\begin{array}{c}\text { Plaintext } \\
\text { (Teori) }\end{array}$ & Indikator \\
\hline $\mathrm{U}$ & $\mathrm{p}$ & $\mathrm{S}$ & $\mathrm{S}$ & Sama \\
\hline $\mathrm{L}$ & $\mathrm{o}$ & $\mathrm{r}$ & $\mathrm{r}$ & Sama \\
\hline $\mathrm{Z}$ & $\mathrm{l}$ & $\mathrm{i}$ & $\mathrm{i}$ & Sama \\
\hline $\mathrm{M}$ & $\mathrm{s}$ & $\mathrm{w}$ & $\mathrm{w}$ & Sama \\
\hline $\mathrm{k}$ & $\mathrm{r}$ & $\mathrm{i}$ & $\mathrm{i}$ & Sama \\
\hline $\mathrm{x}$ & $\mathrm{i}$ & $\mathrm{j}$ & $\mathrm{j}$ & Sama \\
\hline $\mathrm{t}$ & $\mathrm{p}$ & $\mathrm{a}$ & $\mathrm{a}$ & Sama \\
\hline $\mathrm{n}$ & $\mathrm{o}$ & $\mathrm{y}$ & $\mathrm{y}$ & Sama \\
\hline $\mathrm{C}$ & $\mathrm{l}$ & $\mathrm{a}$ & $\mathrm{a}$ & Sama \\
\hline $\mathrm{d}$ & $\mathrm{s}$ & 3 & 3 & Sama \\
\hline$>$ & $\mathrm{r}$ & 2 & 2 & Sama \\
\hline$?$ & $\mathrm{i}$ & 1 & 1 & Sama \\
\hline
\end{tabular}

\subsection{Analisa}

Pada penelitian ini dilakukan pengujian terhadap aplikasi yang telah dirancang. Pada pengujian terhadap desain tampilan telah sesuai dengan yang diharapkan. Selanjutnya saat pengujian perintah program yaitu proses enkripsi dan deskripsi juga telah sesuai dengan yang diharapkan. Dapat dilihat pada pengujian enkripsi menghasilkan indikator yang sama pada masingmasing karakter antara plaintext yang diuji pada aplikasi dengan teori. Pada pengujian deskripsi juga menghasilkan indikator yang sama pada masing-masing karakter antara ciphertext yang diuji pada aplikasi dengan teori. Hal ini dapat dikatakan bahwa proses enkripsi dan deskripsi pada aplikasi telah bekerja dengan baik.

\section{KESIMPULAN}

Dari penelitian ini didapatkan kesimpulan yaitu sebagai berikut:

1. Tampilan desain pada aplikasi sesuai dengan perancangan desain tampilan baik pada tampilan menu utama, tampilan enkripsi dan tampilan deskripsi.

2. Proses enkripsi pada aplikasi dikatakan berhasil karena menghasilkan indikator yang sama antara hasil ciphertext yang dihasilkan aplikasi dengan hasil ciphertext yang dihasilkan teori.

3. Proses deskripsi pada aplikasi dikatakan berhasil karena menghasilkan indikator yang sama antara hasil plaintext yang dihasilkan aplikasi dengan hasil plaintext yang dihasilkan teori

4. Aplikasi ini memiliki kelemahan yaitu mudah dibuka oleh orang yang tidak berhak mengetahui informasi yang telah terenkripsi. Oleh karena itu, aplikasi harus diberi sistem pengaman dalam perancangan aplikasi dengan merancang perintah pengamanan.

5. Saran yang dapat disampaikan untuk pengembangan dalam penelitian ini yaitu melakukan kombinasi terhadap algoritma kriptografi lainnya.

\section{DAFTAR PUSTAKA}

[1] Arjana, P. H, dkk. 2012. Implementasi Enkripsi Data Dengan Algoritma Vigenere Cipher. Seminar Nasional Teknologi Informasi dan Komunikasi 2012 (SENTIKA 2012). 164-169

[2] Ayu, T.K.. 2014. Aplikasi SMS Berbasis Android Dengan Enkripsi Vigenere Running Key. Skripsi.Universitas Sanata Dharma. Yogyakarta.

[3] Ariyus, D.. 2008. Pengantar Ilmu Kriptografi. Yogyakarta: Penerbit Andi. 
[4] Rahmani, Md.K.I., Wadhwa, N., Malhotra, V.. 2012. Alpha-Qwerty Cipher: An Extended Vigenere Cipher. Advanced Computing: An International Journal (ACIJ).Vol.3. No.3 107118

[5] Ardi, A. 2015. Membangun Aplikasi Secure Short Message Service Dengan Sistem Keamanan Menggunakan Alpha-Qwerty Chipher An Extended Vigenere Cipher Berbasis Android. Naskah Publikasi. STMIK AMIKOM. Yogyakarta. 